\title{
NGHIÊN CỨU CÁC ĐẶC TRƯNG BIẾN ĐỘNG CỦA TRƯỜNG NHIẸT ĐỘ BỀ MẠTT VÙNG BIỂN NAM TRUNG BỘ GIAI ĐOẠN 2002-2018
}

\author{
Vũ Hải Đăng ${ }^{1}$, Nguyễn Minh Huấn ${ }^{2}$, Nguyễn Bá Thủy ${ }^{3}$, Đỗ Ngọc Thực ${ }^{1}$
}

Tóm tắt: Các đặc trung biến động của truờng nhiệt độ bề mặt vùng biển Nam Trung Bộ đã đuợc phân tich thống kê dựa trên chuỗi số liệu nhiệt độ bề mặt biển (SST) hàng ngày toàn cầu độ phân giải cao phiên bản 4.1 (MUR-JPL-L4-GLOB-v4.1) tù tháng 6 năm 2002 đến tháng 5 năm 2018 do Trung tâm Luu trũ Phân phối Hải dương học vật lý (PO.DAAC) thuộc Phòng thí nghiệm Sức đẩy Phản lục (JPL) của NASA cung cấp. Các kết quả cho thấy phân bố không gian của trường SST trung bình vùng biển Nam Trung Bộ thay đổi đáng kể theo mùa, cao vào mùa hè và tháp vào mùa đông, chênh lệch trung bình mùa cực đại lên đến $5^{\circ} \mathrm{C}$. Đặc điểm nổi bật là sụ tồn tại của lữ̛i nước lạnh dưới $25^{\circ} \mathrm{C}$ ăn sâu xuống phía nam dọc theo bò̀ biển miền Trung trong mùa đông do ảnh hưởng của gió mùa Đông Bắc và vùng nước mát có nhiệt độ nhỏ hơn $28^{\circ} \mathrm{C}$ noài khơ bò̀ biển Ninh Thuận trong mùa hè là hệ quả của hiện tượng nước trồi do gió mùa Tây Nam. Biến động mùa của truờng SST thay đổi khá lớn theo tùng năm. Phân bố không gian của xu thế biến động SST trung bình năm vùng biển Nam Trung Bộ dao động trong khoảng tù 0,0 đến hơn 0, $6^{\circ} \mathrm{C} / 10$ năm trong giai đoạn 20022018, gần nhu toàn vùng thể hiện xu thế tăng mạn, trù khu vực biển ven bò̀ có xu thế tăng nhẹ. Vùng có xu thế tăng của SST lớn nhất là vùng phía ngoài kinh tuyến 110 , cực đại lên đến hơn $0,6^{\circ} \mathrm{C} / 10$ năm. Tuy nhiên, xu thế biến động SST thể hiện sụ khác nhau rõ rệt theo mùa. Xu thế tăng là chủ đạo trên toàn vùng biển, mưc độ tăng cưc đại xuất hiện trong mùa thu và mùa hè, mùa đông và mùa xuân có xu thế tăng thấp hơn. Xu thế giảm chỉ xuất hiện ở vùng ven bò̀ trong mùa xuân, hè và đông. Đặc biệt trong mùa xuân, vùng biển ven bò̀ tù̀ Quảng Ngãi đến Phú Yên có xu thế giảm mạnh, tốc độ giảm lớn nhất đạt khoảng hơn $-0,4^{\circ} \mathrm{C} / 10$ năm.

Từ khóa: Nhiệt độ bề mặt biển, Biến động mùa và năm nhiều năm, Số liệu vệ tinh, Nam Trung Bộ.

Ban Biên tập nhận bài: 11/12/2019 Ngày phản biện xong: 12/12/2019 Ngày đăng bài: 20/12/2019

\section{Mở đầu}

Theo báo cáo đánh giá lần thứ năm của Ủy ban Liên chính phủ về Biến đổi khí hậu [1], SST trung bình toàn cầu đã tăng kể cả từ đầu thế kỷ 20 và những năm 1950. SST trung bình của Ấn Độ Dương, Đại Tây Dương và Thái Bình Dương đã tăng lần lượt $0,65^{\circ} \mathrm{C}, 0,41^{\circ} \mathrm{C}$ và $0,31^{\circ} \mathrm{C}$ trong giai đoạn 1950-2009. Các nghiên cứu độc lập sử dụng riêng dữ liệu vệ tinh cũng đã xác định được xu thế tăng của SST trung bình toàn cầu giai đoạn gần đây. Mặc dù chuỗi số liệu này tương đối ngắn so với dữ liệu đo đạc thực địa, tuy nhiên bộ dữ liệu vệ tinh có lợi thế là chúng có thể cung cấp vùng phủ gần như toàn cầu, cho phép xác định xu thế toàn cầu. Lawrence và nnk [2] đã so sánh các xu thế SST toàn cầu được xác định từ 16 năm của dữ liệu tái phân tích AVHRR và 8 năm dữ liệu ATSR. Họ đã tìm thấy xu hướng tăng nhất quán 0,09 và $0,13^{\circ} \mathrm{C} / 10$ năm từ dữ liệu AVHRR và ATSR, tương ứng. Tính nhất quán giữa các bộ dữ liệu độc lập này chỉ ra rằng các xu thế này thể hiện cho sự nóng lên thực sự của bề mặt đại dương. Gần đây nhất, Susana M. Barbosa và Ole $\mathrm{B}$. Andersen [3] đã phân tích bộ dữ liệu Nội suy tối ưu phiên bản 2 của NOAA (OI.v2) (cả dữ liệu thực địa và vệ tinh), từ 1982

${ }^{1}$ Viện Địa chất và Địa vật lý biển - VAST

${ }^{2}$ Khoa Khi tuợng Thuỷ văn và Hải dương hoc - HUS

${ }^{3}$ Trung tâm Dư báo khi tượng thủy văn quốc gia

Email:vuhaidang@hotmail.com 


\section{BÀI BÁO KHOA HỌC}

đến 2006. Họ đã chỉ ra rằng sự thay đổi theo thời gian của SST trung bình toàn cầu được đặc trưng bởi một xu hướng ngày càng tăng (ước tính $0,12^{\circ} \mathrm{C} / 10$ năm) và các đỉnh trùng khớp với các thời kỳ El Niño mạnh, đặc biệt như 1982-1983, 1986-1987 và 1997-1998.

Tuy nhiên, xu thế tăng của SST quy mô vùng thể hiện sự khác biệt về biên độ. Tại biển Địa Trung Hải, dựa trên cơ sở dữ liệu vệ tinh từ năm 1985 đến 2006, Nykjaer [4] cho thấy SST đã ấm lên đáng kể khoảng 0,3 và $0,5^{\circ} \mathrm{C} / 10$ năm ở các tiểu lưu vực phía tây và phía đông Địa Trung Hải, tương ứng, rõ rệt nhất trong tháng sáu. Mohamed Shaltout và Anders Omstedt [5] phân tích SST Địa Trung Hải trong giai đoạn gần đây (1982-2012) bằng dữ liệu SST hàng ngày (AVHRR). Những dữ liệu này cho thấy sự nóng lên đáng kể từ $0,24^{\circ} \mathrm{C} / 10$ năm về phía tây của $\mathrm{Eo}$ biển Gibraltar tới $0,51^{\circ} \mathrm{C} / 10$ năm trên Biển Đen. Các nghiên cứu khác cũng chỉ ra rằng xu hướng ấm lên khá mạnh ở Biển Đen. Ginzburg và nnk [6] đã ghi nhận sự nóng lên đáng kể của SST $(0,9$ ${ }^{\circ} \mathrm{C} / 10$ năm) trong giai đoạn 1980 - 2000, sử dụng dữ liệu SST vệ tinh vào ban đêm. Abdulla Sakalli và Nuri Başusta [7] đã phát hiện mức tăng 0,64 ${ }^{\circ} \mathrm{C} / 10$ năm giai đoạn từ 1982-2015, với biến động hàng tháng lớn nhất trong SST là vào cuối mùa hè và mùa thu. Ở Biển Đông, Fang và cs [8] cho rằng trong giai đoạn từ năm 1993 và 2003, nhiệt độ mặt nước biển có xu thế tuyến tính tăng mạnh. Sử dụng bộ dữ liệu nhiệt độ bề mặt biển và băng tạo bởi Trung tâm Hadley (HadISST) cho giai đoạn 1950-2008, Young-Gyu Park và Ara Choi [9] chỉ ra rằng xu thế dài hạn của cả SST mùa đông và mùa hè đều tăng, nhưng kiểu ấm lên và nguyên nhân gây ra là khác nhau. Sự nóng lên mạnh mẽ vào mùa đông xảy ra ở khu vực trung tâm và vào mùa hè ở khu vực phía Nam của Biển Đông.

Riêng vùng biển Nam Trung Bộ, Đinh Văn Uu và $c s[10]$ và Phạm Văn Huấn và Phạm
Hoàng Lâm [11] cũng đã cho thấy tính biến động khá mạnh giữa các năm của trường nhiệt độ tầng mặt dựa trên việc phân tích chuỗi số liệu chỉ vài năm. Phạm Văn Huấn và Phạm Hoàng Lâm [11] đã chỉ ra sự biến thiên giữa các năm của trường nhiệt phụ thuộc vào sự tăng cường hay suy yếu của hai quá trình lớn trong vùng biển: sự xâm nhập của dòng chảy lạnh mùa đông từ phía Đông Bắc biển Đông xuống phía Tây Nam tới vùng nghiên cứu và sự xuất hiện nước trồi ven bờ Trung Bộ và Nam Trung Bộ Việt Nam trong gió mùa Tây Nam. Tuy nhiên, do chỉ sử dụng chuỗi số liệu khá ngắn nên các nghiên cứu này chưa cho thấy những đặc điểm biến động trong dài hạn của trường nhiệt độ tầng mặt, đặc biệt trong xu thế biến động chung của nhiệt độ bề mặt biển toàn cầu.

\section{Nguồn số liệu và phương pháp sử dụng}

Dựa vào bộ số liệu SST hàng ngày toàn cầu độ phân giải cao $(0,01$ độ x 0,01 độ) phiên bản 4.1 (MUR-JPL-L4-GLOB-v4.1) từ tháng 6 năm 2002 đến tháng 5 năm 2018 do Trung tâm Lưu trữ Phân phối Hải dương học vật lý (PO.DAAC) thuộc Phòng thí nghiệm Sức đẩy Phản lực (JPL) của NASA cung cấp, chúng tôi đã tính toán các đặc trưng thống kê của trường SST trung bình tháng, mùa và năm cho từng điểm lưới. Trong đó, mùa xuân là từ tháng 3 đến tháng 5 , mùa hè (mùa gió Tây Nam) từ tháng 6 đến tháng 8 , mùa thu từ tháng 9 đến tháng 11 và mùa đông (mùa gió Đông Bắc) từ tháng 12 đến tháng 2 năm sau. Sau đó, phương pháp bình phương nhỏ nhất trong phân tích hồi quy tuyến tính được sử dụng để xác định xu thế biến động của trường SST trung bình mùa và năm trong nhiều năm tại từng điểm lưới số liệu. So sánh số liệu SST trung bình ngày quan trắc tại trạm Phú Quý với số liệu quan trắc từ vệ tinh năm 2013 cho thấy hệ số tương quan giữa hai bộ số liệu là khá cao lên đến hơn 0,9 (hình 1). 


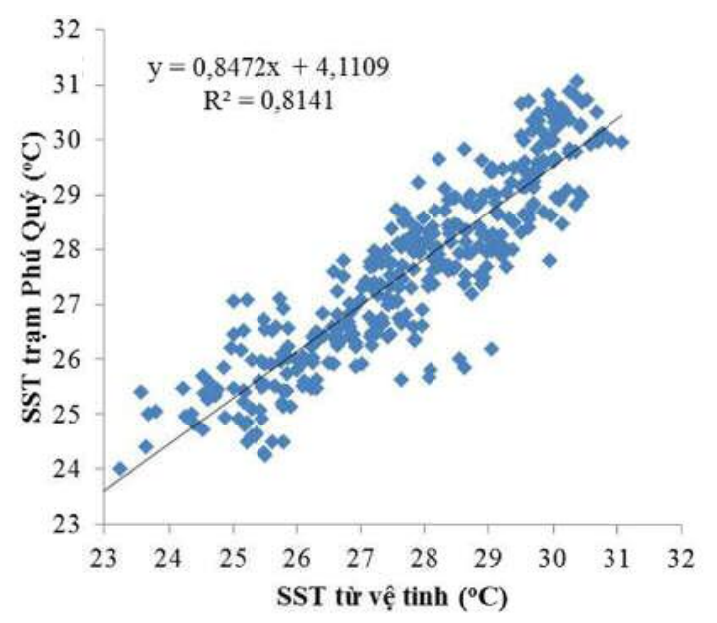

Hình 1. Tương quan giũa số liệu SST trung bình ngày quan trắc tại trạm Phú Quý với số liệu quan trắc tù̀ vệ tinh năm 2013
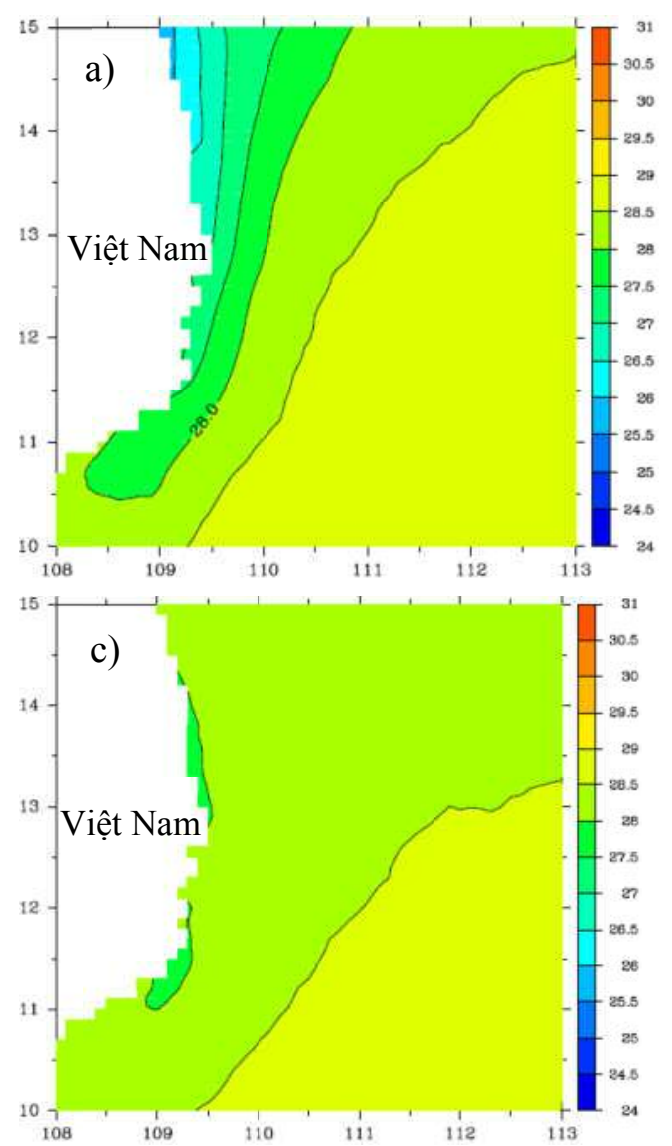

\section{Kết quả và thảo luận}

Các kết quả tính toán cho thấy phân bố không gian của trường SST trung bình nhiều năm theo mùa tại vùng biển Nam Trung Bộ cũng thay đổi đáng kể. Trong mùa xuân, nhiệt độ bề mặt biển dao động từ khoảng 25 đến hơn $28,5^{\circ} \mathrm{C}$ (hình $2 \mathrm{a})$, với xu thế tăng dần từ phía bắc xuống phía nam và từ bờ ra khơi. Do vẫn còn chịu ảnh hưởng của sự xâm nhập của dòng chảy lạnh dọc ven bờ biển miền Trung, nền nhiệt vùng ven bờ tại khu vực phía bắc thấp hơn vùng ngoài khơi khoảng $3^{\circ} \mathrm{C}$ và hơn $1,5^{\circ} \mathrm{C}$ đối với khu vực phía nam. Trong mùa hè, $\mathrm{SST}$ dao động từ khoảng 28 đến hơn $29,5^{\circ} \mathrm{C}$ (hình $2 \mathrm{~b}$ ), cao nhất tại khu vực phía bắc khoảng hơn $29,5^{\circ} \mathrm{C}$.
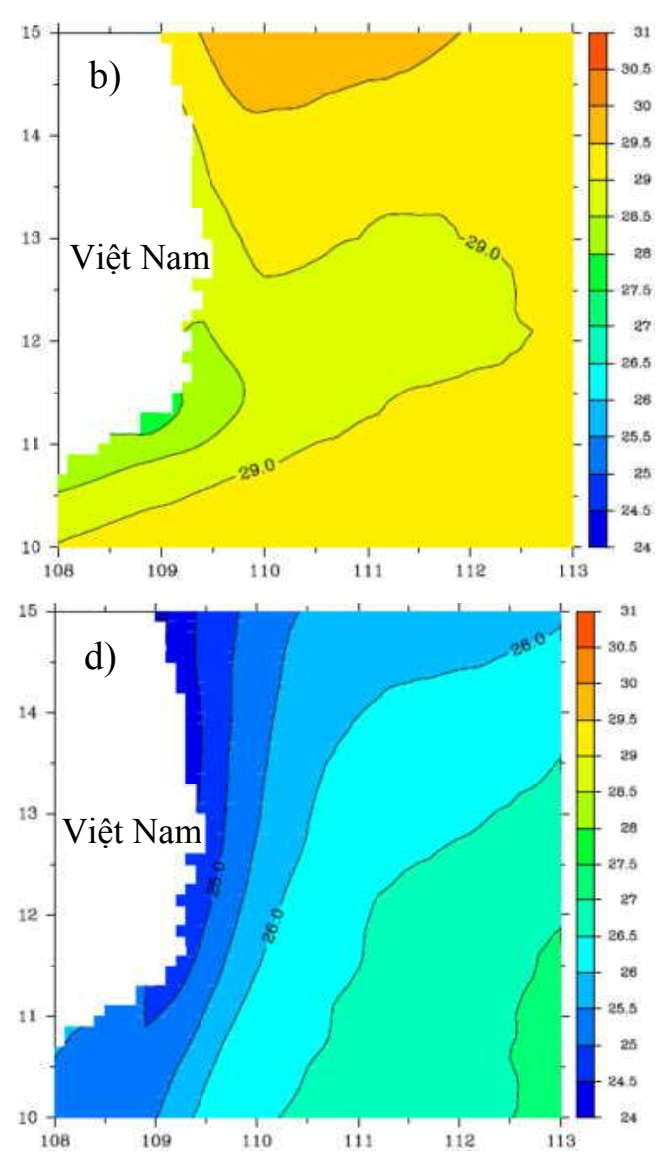

Hình 2. So đồ phân bố không gian của SST trung bình mùa nhiều năm (giai đoạn 6/2002-5/2018, đon vị ${ }^{\circ}$ C): a) mùa xuân; b) mùa hè; c) mùa thu; và d) mùa đông

Tại khu vực phía nam, xuất hiện một vùng nước có nhiệt độ thấp hơn nằm lệch về phía bờ biển Việt Nam có tâm nằm ở vùng ven bờ tỉnh Ninh Thuận do hoạt động nước trồi trong gió mùa Tây Nam. Trong mùa thu, thay đổi SST theo không gian không lớn, trung bình toàn vùng đạt khoảng $28,5^{\circ} \mathrm{C}$ (hình $2 \mathrm{c}$ ). Trong mùa đông, SST dao động từ khoảng 24 đến hơn $27^{\circ} \mathrm{C}$ (hình $2 \mathrm{~d}$ ), thấp nhất tại khu vực dọc bờ biển Quảng $\mathrm{Ngãi}$ và Phú Yên chỉ khoảng $24,5^{\circ} \mathrm{C}$. Do ảnh hưởng 
của gió mùa Đông Bắc nước lạnh tràn xuống phía nam theo hướng Đông Bắc - Tây Nam khi gặp dòng chảy mạnh ở ven bờ Việt Nam đem khối nước lạnh nhiệt độ thấp (dưới $24^{\circ} \mathrm{C}$ ) của vịnh Bắc Bộ tăng cường, làm cho đường đẳng nhiệt độ $25^{\circ} \mathrm{C}$ bị ấn sâu xuống phía nam áp sát vào vùng ven bờ tạo thành lưỡi nước lạnh đến tận khu vực ven bờ Ninh Thuận. Sự chênh lệch nhiệt độ giữa vùng bờ và ngoài khơi tại khu vực phía nam đạt cực đại lên đến gần $3^{\circ} \mathrm{C}$. Biên độ chênh lệch $\mathrm{SST}$ trung bình giữa mùa đông và mùa hè lớn nhất có thể lên đến $4-5^{\circ} \mathrm{C}$ ở vùng ven bờ và $2-3^{\circ} \mathrm{C}$ ở vùng ngoài khơi. Chênh lệch này tại khu vực phía bắc thường cao hơn khu vực phía nam.

Phân bố không gian của xu thế biến động SST vùng biển Nam Trung Bộ dao động trong khoảng từ 0,0 đến hơn $0,6^{\circ} \mathrm{C} / 10$ năm (hình $3 \mathrm{a}$ ), với xu hướng tăng từ bờ ra khơi. Có thể thấy gần như toàn vùng thể hiện xu thế tăng mạnh của SST, trừ khu vực biển ven bờ có xu thế tăng nhẹ. Vùng có $x u$ thế tăng của SST lớn nhất là vùng phía ngoài kinh tuyến 110 , cực đại lên đến hơn $0,6^{\circ} \mathrm{C} / 10$ năm. Chi tiết hơn về xu thế biến động SST trung năm tại một vị trí cụ thể có thể quan sát trên hình $3 b$.
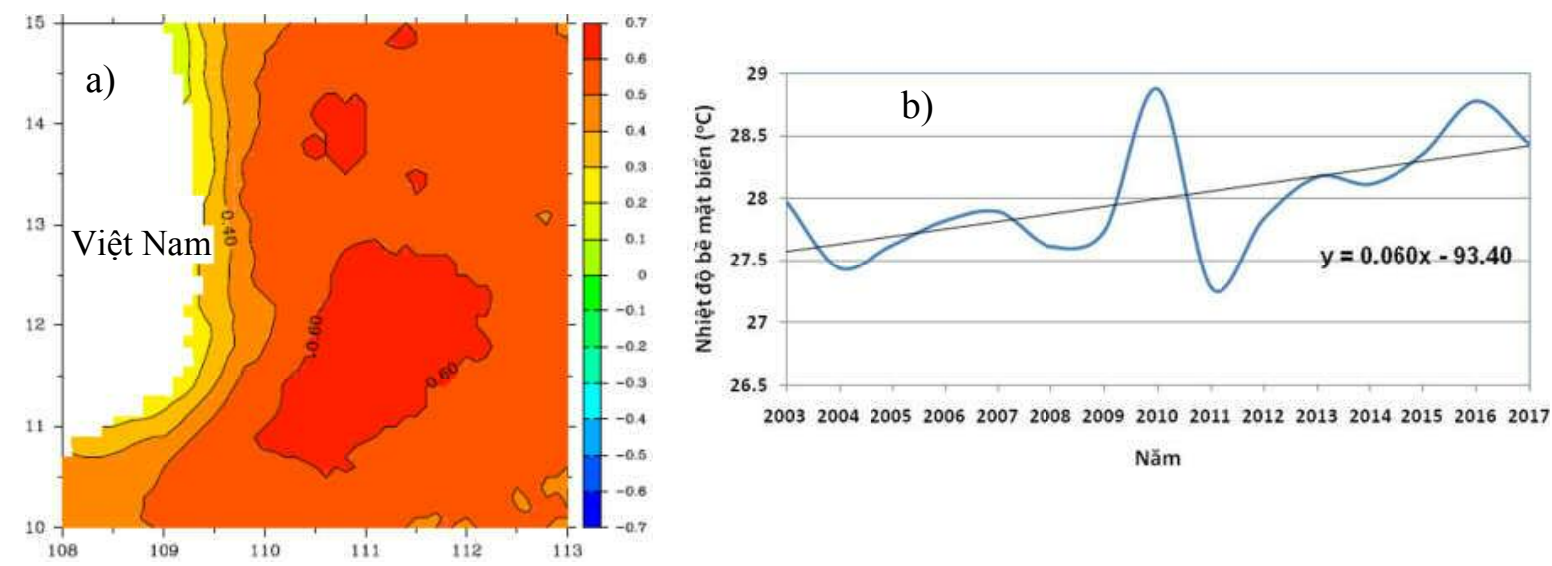

Hình 3. a) So đồ phân bố không gian của xu thế biến động SST trung bình năm và b) xu thế biến động SST trung bình năm tại vị trí $11^{\circ}$ vĩ Bắc - $110^{\circ}$ kinh Đông (giai đoạn 2003-2017, đơn vị ${ }^{\circ} \mathrm{C}$ )

Xu thế biến động SST mùa vùng biển Nam Trung Bộ cũng thể hiện sự khác nhau rõ rệt. Xu thế biến động trong mùa xuân cho thấy mức độ tăng của SST tại khu vực phía nam cao hơn hẳn cực đại lên đến hơn $0,6^{\circ} \mathrm{C} / 10$ năm (hình $4 \mathrm{a}$ ). Tại khu vực phía bắc, vùng ngoài khơi tốc độ tăng của SST chỉ đạt khoảng từ 0 đến hơn $0,3^{\circ} \mathrm{C} / 10$ năm, riêng vùng biển ven bờ SST có xu thế giảm, tốc độ giảm lớn nhất đạt khoảng hơn $0,4^{\circ} \mathrm{C} / 10$ năm. Trong mùa hè, $\mathrm{xu}$ thế tăng của SST diễn ra trên hầu như toàn vùng biển Nam Trung Bộ, trừ vùng ven biển các tỉnh Khánh Hòa và Ninh Thuận có xu thế giản nhẹ (hình 4b). Phía ngoài khơi kinh tuyến 110 , tốc độ tăng của SST đều lớn hơn $0,5^{\circ} \mathrm{C} / 10$ năm. Trong mùa thu, toàn bộ vùng nghiên cứu $\mathrm{SST}$ có xu thế tăng mạnh từ khoảng 0,3 đến hơn $0,9^{\circ} \mathrm{C} / 10$ năm, đặc biệt từ vĩ tuyến 12 trở lên tốc độ tăng của SST đều lớn hơn $0,6^{\circ} \mathrm{C} / 10$ năm (hình $4 \mathrm{c}$ ). Về mùa đông, phân bố xu thế biến động SST không đồng đều. Vùng ngoài khơi phía ngoài kinh độ 109,5 thể hiện xu thế tăng của $\mathrm{SST}$ từ khoảng 0,2 đến dưới $0,5^{\circ} \mathrm{C} / 10$ năm. Tại vùng ven bờ tốc độ tăng nhỏ hơn chỉ khoảng 0,0 dến dưới $0,2^{\circ} \mathrm{C} / 10$ năm (hình 4d).

Theo Young-Gyu Park và Ara Choi [9] thì sự khác nhau giữa xu thế biến động nhiệt độ bề mặt biển theo mùa trên biển Đông là do sự biến động của dòng nhiệt tổng cộng đi vào bề mặt biển và hoạt động của trường gió mùa Đông Bắc trong mùa đông và gió mùa Tây Nam trong mùa hè. Tuy nhiên do khuôn khổ nghiên cứu của đề tài có hạn nên việc tìm hiểu cơ chế biến động cho từng mùa sẽ được thực hiện trong những nghiên cứu tiếp theo. 

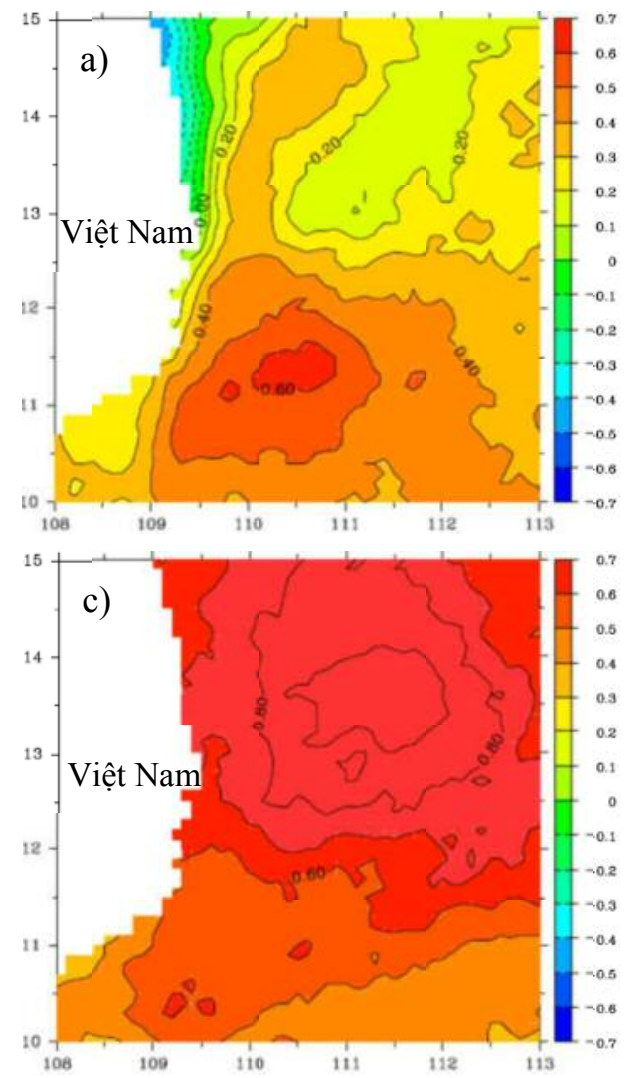
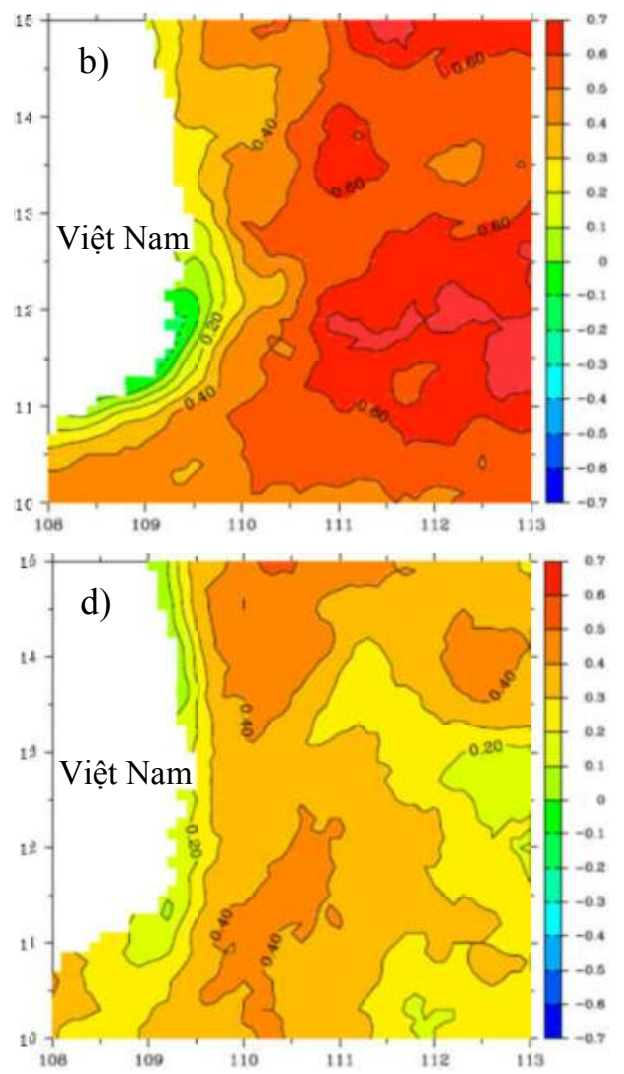

Hình 4. So đồ phân bố không gian của xu hương biến động SST trung bình mùa (giai đoạn 6/2002-5/2018, đon vị ${ }^{\circ}$ C): a) mùa xuân; b) mùa hè; c) mùa thu; và d) mùa đông

\section{Kết luận}

Dựa trên bộ số liệu SST hàng ngày toàn cầu quan trắc từ vệ tinh, các đặc trưng biến động theo không gian và thời gian của trường SST tại vùng biển Nam Trung bộ đã được phân tích và đánh giá. Các kết quả cho thấy phân bố không gian của trường SST trung bình vùng biển Nam Trung Bộ thay đổi đáng kể theo mùa, cao vào mùa hè và thấp vào mùa đông chênh lệch trung bình mùa cực đại lên đến $5^{\circ} \mathrm{C}$. Đặc điểm nổi bật là sự tồn tại của lưỡi nước lạnh dưới $25^{\circ} \mathrm{C}$ ăn sâu xuống phía nam dọc theo bờ biển miền Trung trong mùa đông do ảnh hưởng của gió mùa Đông Bắc và vùng nước mát có nhiệt độ nhỏ hơn $28^{\circ} \mathrm{C}$ ngoài khơi bờ biển Ninh Thuận trong mùa hè là hệ quả của hiện tượng nước trồi do gió mùa Tây Nam. Biến động mùa của trường SST thay đổi khá lớn theo từng năm. Phân bố không gian của xu thế biến động SST trung bình năm vùng biển Nam Trung bộ dao động trong khoảng từ 0,0 đến hơn $0,6^{\circ} \mathrm{C} / 10$ năm, gần như toàn vùng thể hiện xu thế tăng mạnh, trừ khu vực biển ven bờ có xu thế tăng nhẹ. Vùng có xu thế tăng của SST lớn nhất là vùng phía ngoài kinh tuyến 110 , cực đại lên đến hơn $0,6^{\circ} \mathrm{C} / 10$ năm. Tuy nhiên, xu thế biến động SST thể hiện sự khác nhau rõ rệt theo mùa. Xu thế biến động SST thể hiện sự khác nhau rõ rệt theo mùa. Xu thế tăng là chủ đạo trên toàn vùng biển, mức độ tăng cực đại xuất hiện trong mùa thu và mùa hè, mùa đông và mùa xuân có xu thế tăng thấp hơn. Xu thế giảm chỉ xuất hiện ở vùng ven bờ trong mùa xuân, hè và đông. Đặc biệt trong mùa xuân, vùng biển ven bờ từ Quảng Ngãi đến Phú Yên có xu thế giảm mạnh, tốc độ giảm lớn nhất đạt khoảng hơn $-0,4^{\circ} \mathrm{C} / 10$ năm.

Tuy nhiên do khuôn khổ nghiên cứu của đề tài có hạn nên việc tìm hiểu cơ chế biến động cho từng mùa sẽ được thực hiện trong những nghiên cứu tiếp theo. 


\section{BÀI BÁO KHOA HỌC}

\section{Tài liệu tham khảo}

1. Hoegh-Guldberg, O., Cai, R., Poloczanska, E.S., Brewer, P.G., Sundby, S., Hilmi, K., Fabry, V.J., Jung, S., (2014), The Ocean. In: Climate Change 2014: Impacts, Adaptation, and Vulnerability. Part B: Regional Aspects. Contribution of Working Group II to the Fifth Assessment Report of the Intergovernmental Panel on Climate Change (Barros, V.R., C.B. Field, D.J. Dokken, M.D. Mastrandrea, K.J. Mach, T.E. Bilir, M. Chatterjee, K.L. Ebi, Y.O. Estrada, R.C. Genova, B. Girma, E.S. Kissel, A.N. Levy, S. MacCracken, P.R. Mastrandrea, and L.L. White (eds.)). Cambridge University Press, Cambridge, United Kingdom and New York, NY, USA, 1655-1731.

2. Lawrence, S.P., Llewellyn-Jones, D.T., Smith, S.J., (2004), The measurement of climate change using data from the Advanced Very High Resolution and Along Track Scanning Radiometers. Journal of Geophysical Research, 109, C08017, doi:10.1029/2003JC002104.

3. Barbosa, S.M., Andersen, O.B., (2009), Trend patterns in global sea surface temperature. International Journal of Climatology, 29 (14), 2049-2055.

4. Nykjaer, L., (2009), Mediterranean Sea surface warming 1985-2006. Climate Research, 39 (1), 11-17.

5. Shaltout, M., Omstedt, A., (2014), Recent sea surface temperature trends and future scenarios for the Mediterranean Sea. Oceanologia, 56 (3), 411-443.

6. Ginzburg, A.I., Kostianoy, A.G., Sheremet, N.A., (2004), Seasonal and interannual variability of the Black Sea surface temperature as revealed from satellite data (1982-2000). Journal of Marine Systems, 52 (1), 33-50.

7. Sakalli, A., Başusta, N., (2018), Sea surface temperature change in the Black Sea under climate change: A simulation of the sea surface temperature up to 2100. The International Journal of Climatology, 38 (13), 4687-4698.

8. Fang, G., Chen, H., Wei, Z., Wang, Y., Wang, X., Li, C., (2006), Trends and interannual variability of the South China Sea surface winds, surface height, and surface temperature in the recent decade. Journal of Geophysical Research, 111, C11S16.

9. Park, Y.G., Choi, A., (2017), Long-term changes of South China Sea surface temperatures in winter and summer. Continental Shelf Research, 143, 185-193.

10. Đinh Văn U’u, Đoàn Bộ, Hà Thanh Hương, Phạm Hoàng Lâm, Hoàng Đức Hiền (2005), Tưong quan biến động điều kiện môi truờng và ngu truòng nghề câu cá ngù đại dương ở vùng biển khơ nam Việt Nam. Tạp chí Khoa học ĐHQGHN, KHTN \& CN, 3PT, 108-117.

11. Phạm Văn Huấn và Phạm Hoàng Lâm (2006), Một số kết quả khai thác cơ sở dĩ liệu hải duơng họ để nghiên cứu biến động môi truoòng nước vùng biển xa bò̀ Việt Nam. Tạp chí Khí tượng thủy văn, 548, 28-38. 


\title{
STUDY CHARACTERISTICS OF SEA SURFACE TEMPERATURE VARIATION IN THE SOUTH CENTRAL SEA REGION OF VIETNAM DURING THE PERIOD OF 2002-2018
}

\author{
Vu Hai Dang', Nguyen Minh Huan², Nguyen Ba Thuy ${ }^{3}$, Do Ngoc Thuc ${ }^{1}$ \\ ${ }^{1}$ Institute of Marine Geology and Geophysics - VAST \\ ${ }^{2}$ Faculty of Meteorology, Hydrology, and Oceanography - HUS \\ ${ }^{3}$ National Hydrological Forecasting Center
}

\begin{abstract}
The characteristics of temporal and spatial variability of the sea surface temperature in the South Central sea region of Vietnam have been analyzed and evaluated based on MUR-JPLL4-GLOB-v4.1 dataset from June 2002 to May 2018 provided by The Physical Oceanography Distributed Active Archive Center at NASA's Jet Propulsion Laboratory. The results show that the average SST spatial distribution varies significantly by season, high in summer and low in winter, the average maximum seasonal difference is up to $5^{\circ} \mathrm{C}$. Especially, the presence of cold water tongue below $25^{\circ} \mathrm{C}$ goes deep south along the Central Coast in winter due to the influence of the Northeast monsoon and cool water lower than $28^{\circ} \mathrm{C}$ offshore Ninh Thuan coastline in the summer is the result of the upwelling due to the Southwest monsoon. Seasonal fluctuations of SST field considerable change from year to year. Spatial distribution of the average SST trend in the South Central sea region of Vietnam ranges from 0.0 to more than $0.6^{\circ} \mathrm{C} / 10$ years during 2002-2018. Almost the whole region showed a strong uptrend, except for the coastal area that tended to increase slightly. The region with the largest uptrend of SST is the area outside the meridians 110, which reaches a maximum of more than $0.6^{\circ} \mathrm{C} / 10$ years. However, the SST trend shows marked seasonal differences. The uptrend is dominant across the sea, with the maximum level occurring in the fall and summer, the winter and spring tend to increase lower. The downward trend only appears in coastal areas in spring, summer and winter. Especially in the spring, coastal areas from Quang Ngai to Phu Yen tend to decrease sharply, the largest reduction rate reaches over $-0.4^{\circ} \mathrm{C} / 10$ years.
\end{abstract}

Keywords: Sea surface temperature, Seasonal and annual fluctuations, Satellite data, the South Central sea region of Vietnam. 